Original Article (short paper)

\title{
Effects of myocardial infarction and an intensive exercise bout on kinetic of lactate, and LDH-B levels in spontaneously hypertensive rats
}

\author{
Rafael Aguiar Marschner ${ }^{1,2}$ (D), Jocelito Bijoldo Martins ${ }^{1,2}$ (D), Melissa Medeiros Markoski ${ }^{3}$ (D), \\ Alexandre Machado Lehnen ${ }^{1}$ (D), Maximiliano Isoppo Schaun ${ }^{1,4}$ (iD \\ ${ }^{I}$ Fundação Universitária de Cardiologia, Instituto de Cardiologia, Porto Alegre, RS, Brasil. \\ ${ }^{2}$ Faculdade Sogipa, Escola de Educação Física, Porto Alegre, RS, Brasil. \\ ${ }^{3}$ Universidade Federal de Ciências da Saúde de Porto Alegre, Departamento de Ciências Básicas \\ da Saúde, Programa de Pós-Graduação em Biociências, Porto Alegre, RS, Brasil. \\ ${ }^{4}$ Universidade Luterana do Brasil, Curso de Educação Física, Gravatai, RS, Brasil.
}

\begin{abstract}
Aims: This study aimed to evaluate the kinetics of lactate and lactate dehydrogenase B (LDH-B) protein levels as well as the maximum effort capacity of spontaneously hypertensive rats (SHRs) with experimental acute myocardial infarction (AMI). Methods: thirty-two SHRs were divided into ( $\mathrm{n}=8 /$ group): $\mathrm{S}$ (sham), SE (sham+exercise), I (AMI), and IE (AMI+exercise). A maximum exercise test (treadmill) was evaluated before AMI or sham surgery. Echocardiography was performed $48 \mathrm{~h}$ after the surgery. Lactacidemia was assessed at rest and during an intense exercise bout (48h after echocardiography). A two-way ANOVA followed by the post-hoc (Bonferroni) test was used, $\mathrm{p}<0.05$. Results: In the end, the heart was removed for analysis of LDH-B. AMI resulted in lower cardiac output ( $\mathrm{S} v s$ I: $\Delta 51.3 \%, \mathrm{p}<0.001$ ), ejection fraction (S $v s$ I: $\Delta 60.5 \%, \mathrm{p}<0.001$ ) and shortening fraction (S $v s$ I: $\Delta 72.4 \%, \mathrm{p}<0.001$ ). The IE showed a reduction in exercise capacity when compared with pre-AMI values $(1.50 \pm 0.1 v s 1.38 \pm 0.2 \mathrm{~km} / \mathrm{h}$; $\mathrm{p}=0.030)$ but not when compared with SE $(1.41 \pm 0.3$ s $1.38 \pm 0.2 \mathrm{~km} / \mathrm{h} ; \mathrm{p}=0.208)$. During the exhaustion exercise session, IE group showed lower lactacidemia at $12 \min (\Delta 9.7 \%, \mathrm{p}=0.042)$ and $18 \min (\Delta 8.3 \%, \mathrm{p}=0.038)$. No differences were observed in the protein level of LDH-B among the groups $(\mathrm{p}=0.573)$. However, when the AMI factor was considered alone, LDH-B expression was lower (sham vs AMI rats, $\mathrm{p}=0.040$ ). Conclusion: LDH-B protein levels in cardiac tissue appear to be associated with AMI only. Furthermore, AMI induced a reduction in exercise capacity but did not affect lactacidemia during the intense exercise bout.
\end{abstract}

Keywords: lactate dehydrogenase, acute myocardial infarction, bioenergetics, lactacidemia, intense exercise bout, rats.

\section{Introduction}

Cardiovascular diseases remain major causes of morbidity and mortality worldwide ${ }^{1}$, among which systemic arterial hypertension (SAH) stands out ${ }^{2,3}$. SAH is a multifactorial condition that precedes, in large part, fatal outcomes such as acute myocardial infarction (AMI) and stroke $e^{4,5}$. The AMI leads to a process known as ventricular remodeling $^{6,7}$ and one of the functional cardiac alterations of remodeling are changes in bioenergetic processes ${ }^{8}$.

Under normal conditions, free fatty acids (FFA) are the main energetic substrate of the heart, with participation ranging from $60 \%$ to $90 \%{ }^{9-11}$. By-products of FFA are oxidized through $\beta$-oxidation to produce ATP to maintain contractile viability. A critical point is when myocardial ischemia leads to a series of metabolic changes in the cardiomyocytes, such as blockage of fatty acid oxidation, increased anaerobic glycolysis, and lactic acid accumulation $^{12}$. Hence, this metabolic disorder may lead to functional deficits in the myocardial mitochondrial, which contribute to cardiac hypertrophy ${ }^{7}$. Yet, with regards to metabolic changes, the heart can reduce lactic acid concentration in the cardiac cells using it as an energetic substrate $^{13}$ by action of lactate dehydrogenase B (LDH-B). Therefore, LDH-B plays an important cardio-protective role in the myocardial ischemia, helping pyruvate to accept the hydrogen atom from $\mathrm{NADH}^{+}$, decreasing lactic acid concentration in the cardiomyocytes ${ }^{14}$. However, evidence has shown that the LDH-B protein expression decreased due to $\mathrm{AMI}^{15}$.

On the other hand, during moderate/intense exercise, there is an increase in blood lactate levels proportional to increased exercise intensity ${ }^{16,17}$. Yet, it was reported that exercise training (swimming, $\sim 30 \mathrm{~min} /$ day for 35 days) elevated cardiac LDH activity ${ }^{18}$. Therefore, it could give to the heart tissue a greater capacity for lactate utilization as an energetic substrate, which results in a reduction of lactic acid concentration in the infarcted heart. Regarding exercise and cardiac function after AMI, Trueblood et al. ${ }^{19}$ showed a progressive impairment in exercise capacity 
post-AMI, but the evaluation considered the volume (distance run) of exercise, not the intensity (maximum effort capacity). Thus, as an approach to these points, we aimed to evaluate the LDH-B protein levels in the cardiac tissue and the maximum effort capacity of spontaneously hypertensive rats (SHRs) with experimental AMI.

\section{Methods}

\section{Ethics}

All animal experimental procedures followed the Guiding Principles in the Care and Use of Animals in Research in agreement with the Brazilian Council for using the animal in research (CONCEA/BR). The study was approved by the Research Ethics Committee of Instituto de Cardiologia/RS, protocol \#UP:4871-13.

All animals were bred and kept under standard laboratory animal house conditions at the Animal Production and Research Unit of the Center for Scientific and Technological Development of Fundação Estadual de Produção e Pesquisa em Saúde do Rio Grande do Sul, Brazil. They were fed with standard balanced rat animal chow, provided water ad libitum, and kept in special cages exposed to a 12-hour light and 12-hour dark cycle (6 a.m. $/ 6$ p.m.) in a $20-25^{\circ} \mathrm{C}$ temperature-controlled room.

\section{Animals}

To create a simulation environment that precedes an AMI, we chose to work with spontaneously hypertensive rats $^{20}$ because hypertension increases by $\sim 40 \%$ the likelihood of an ischemic event ${ }^{21}$. Thus, we evaluated 32 male SHRs, 3 months old, and they were distributed in 4 groups ( $\mathrm{n}=8$ per group): sham-operated rats without intense exercise session (S); sham-operated rats + intense exercise session (SE); acute myocardial infarction induced by left coronary artery ligation (I); acute myocardial infarction induced by left coronary artery ligation + intense exercise session (IE). The experimental design is shown in Figure 1.

\section{Blood pressure}

Blood pressure was measured using a tail-cuff system (Model 229, IITC Life Science Inc.) at the initiation of the protocol to confirm the hypertensive condition of the animals. All animals were placed in a restrainer for 15 minutes with a cuff attached to their tail, and the blood pressure was recorded. The animals were subjected previously to an adaptation period to get used to this procedure that was repeated in three days. Blood pressure measures obtained from day 4 were considered valid ${ }^{22}$.

\section{Coronary artery ligation and sham surgery}

Myocardial infarction was induced according to a procedure previously described in the literature ${ }^{23}$. Briefly, animals were placed in the dorsal decubitus position and anaesthetized with ketamine $(70 \% / \mathrm{kg}$ bodyweights) and xylazine $(35 \% / \mathrm{kg}$ bodyweights) administered intraperitoneally. After orotracheal intubation, animals were submitted to mechanical ventilation with a Harvard ventilator, Model 683 (Holliston, MA, USA). A surgical incision was made in the skin along the left sternal margin, and divulsion of the pectoral and transverse muscle was carried out. Thoracotomy was carried out in the second intercostal space, and the thorax was opened without the exteriorization of the heart. The left anterior descending coronary artery was identified and occluded with a 6-0 mononylon suture between the left atrial appendage margin and the pulmonary artery. The thoracic cavity was then closed with a 5-0 mononylon thread, the muscles were repositioned and the skin sutured. All animals received analgesics after the surgical procedure (butorphanol $2 \mathrm{mg} / \mathrm{kg}$ ). Infarcted animals were considered those with an ejection fraction $\leq 50 \%$ and infarcted area (akinetic) $\geq 30 \%{ }^{23,24}$. Animals that were subjected to a similar surgical proce-

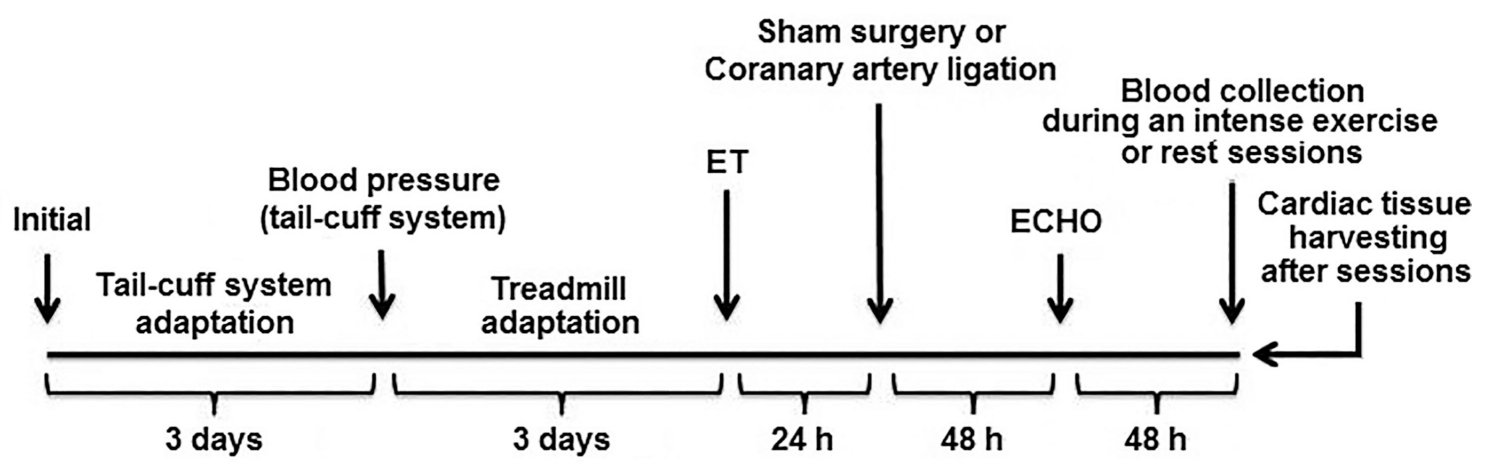

Figure 1 - Experimental design. A 3-day adaptation for acquisition of blood pressure by the tail was performed. On the 4th day, blood pressure and heart rate were recorded. Then, the animals were allowed to adjust to exercise on a treadmill for 3 days $(0.3 \mathrm{~km} / \mathrm{h}$, $15 \mathrm{~min} / \mathrm{day})$. On the 4 th day, the maximal exercise test was performed. Twenty-four hours later, the animals underwent sham surgery or acute myocardial infarction induced by left coronary artery ligation. AMI was confirmed after 48 hours by echocardiography (ECHO). Finally, blood was collected from the animals during an intense exercise session (SE and IE groups) or at rest for the same period (S and I groups). The heart was removed immediately after this procedure. 
dure, but without coronary artery ligation, were used as sham operated.

\section{Echocardiography}

Forty-eight hours after the AMI and Sham procedures, the animals were placed in the left lateral decubitus position $\left(45^{\circ}\right)$ under anesthesia. The anesthesia consisted of a mixture of medical oxygen at $2 \mathrm{~L} / \mathrm{min}$ attached to an isoflurane vaporizer that converted the gas mixture into vapor to be administered to the rats. The EnVisor HD System, Philips Medical (Andover, MA, USA) was used, with a $12-3-\mathrm{MHz}$ transducer, 2-cm deep, and fundamental harmonic imaging. Images were captured by a trained operator with experience in animal echocardiography. The measurements and calculations were performed according to the methods proposed by ${ }^{25}$. Stroke volume (Vs), diastolic ventricular volume (Vd), LV ejection fraction, and cardiac output were obtained as described $\mathrm{in}^{26}$.

\section{Maximal exercise test}

Maximum effort capacity was measured using the exercise test as described in the literature ${ }^{27}$. First, all rats were subjected to an adaptation period on the treadmill at a speed of $0.3 \mathrm{~km} / \mathrm{h}$ for 15 minutes for three consecutive days. The maximal exercise test was then performed individually at an initial speed of $0.3 \mathrm{~km} / \mathrm{h}$ with increments of $0.3 \mathrm{~km} / \mathrm{h}$ every 3 minutes until voluntary exhaustion of the animal. Finally, the maximum speed was recorded.

\section{Blood lactate levels and glucose levels}

Ninety-six hours after AMI, an exercise test with progressive intensities was administered in the same way as the maximum speed test for analysis of the lactate curve and maximum speed test post-MI. Thus, lactacidemia was measured in the basal moment, and in each level of the test $\left(3,6,9,12,15\right.$ and $18^{\text {th }}$ minute). To prevent pain for the animal, an anesthetic was placed on the tip of its tail (Labcaina $20 \mathrm{mg} / \mathrm{g}$, PHARLAB, Lagoa da Prata/MG, Brazil). Thus, it was possible to draw a drop of blood, through a "pike" in the animal's tail tip with a needle (BD PrecisionGlide $^{\mathrm{TM}}$ de 1,20 x $40 \mathrm{~mm}$ ). A lactimeter (Accutrend Plus Roche) with the respective reagent strips was used to measure lactate. Animals that did not perform maximal exercise had the lactacidemia collected at rest at the same time points.

Glucose levels were measured using an ACCUCHEK Active blood glucose system and test strips (Roche Diagnostics, Mannheim, Germany).

\section{LDH-B analysis}

Cardiac tissue was prepared by homogenization using a mechanical tissue homogenizer (Marconi, Piracicaba, Brazil). Then, the samples underwent two cycles of freezing (liquid nitrogen) and thawing (in a water bath, $37^{\circ} \mathrm{C}$ ). Finally, the samples were subjected to centrifuga- tion (Eppendorf model 5804R) at 10,000 rpm for $10 \mathrm{~min}-$ utes and the supernatants were collected and stored in a -80 Ultrafreezer until use.

The LDH-B protein levels in the cardiac tissue were analyzed by ELISA (USBIO), according to the manufacturer's instructions. All samples were analyzed in triplicate. The optical densities were measured in a spectrophotometer (Spectramax M2e, Molecular Devices), $450 \mathrm{~nm}$, at a temperature of $25^{\circ} \mathrm{C}$, with a reduction of background $(570 \mathrm{~nm})$. The baseline measurements were obtained through linear regression of 4 parameters. All sample data were calculated (Excel, Microsoft) and expressed in picograms of protein per milliliter $(\mathrm{pg} / \mathrm{mL})$.

\section{Statistical analyses}

Data normality was evaluated using the ShapiroWilk test, and data were expressed as the means and standard deviations. Differences were assessed using two-way ANOVA followed by the post-hoc Bonferroni test. The factors used in ANOVA were "sham surgery/induction of acute myocardial infarction" and "rest/exercise", and the interaction between these factors. All analyses were performed using SPSS (v22) and a level of significance was set at $5 \%$ for all tests.

\section{Results}

Table 1 shows the baseline characteristics of the study groups. The results indicate that all animals began the experiment with the same body weight. Furthermore, the stroke blood pressure and heart rate were not different between the groups as expected. Likewise, the maximal exercise test showed similar values to each other at baseline. Animals from the IE group showed a reduction in maximum exercise capacity, when compared to the preacute myocardial infarction period (Table 1: $1.50 \pm 0.1 \mathrm{vs}$ $1.38 \pm 0.2 \mathrm{~km} / \mathrm{h} ; \mathrm{p}=0.030$ ), but not when compared with those from the SE group (SE: $1.41 \pm 0.3 v s$ IE: $1.38 \pm 0.2$ $\mathrm{km} / \mathrm{h} ; \mathrm{p}=0.208$ ).

After induction of AMI, it was observed that the kinetic area between animals I and IE did not differ (Figure 2). In response to AMI, I and IE rats showed: (a) lower cardiac output (S vs I: $\Delta 51.3 \%$; SE $v$ IE: $\Delta 46.0 \%$; $\mathrm{p}<0.001$ for all comparisons), (b) lower left ventricular ejection fraction (S $v s$ I: $\Delta 60.5 \%$; SE $v s$ IE: $\Delta 51.0 \%$; $\mathrm{p}<0.001$ for all comparisons) and (c) a shortening fraction of the left ventricle (S vs I: $\Delta 72.4 \%$; SE $v s$ IE: $\Delta 66.6 \% ; \mathrm{p}<0.001$ for all comparisons). In addition, there were no differences in these parameters between groups I and IE.

Figure 3 shows the variation in blood lactate levels in the resting and exercise groups. There was a difference in the interaction between group and time $(p<0.001)$. Therefore, the animals of group I showed a slight increase in lactate levels compared with the $\mathrm{S}$ group during the per- 
iod of rest (basal time up to 18 minutes) (p-value of each time is shown in Figure 3A). Similarly, at baseline (time 0 of the exercise session), the IE animals also had higher blood lactate levels compared to the SE animals

Table 1 - Baseline characteristics of the study groups.

\begin{tabular}{|c|c|c|c|c|c|}
\hline & $\mathbf{S}$ & SE & $\mathbf{I}$ & IE & p (interaction) \\
\hline Body weight (g) & $295.5 \pm 7.8$ & $319.8 \pm 8.6$ & $315.0 \pm 8.6$ & $312.0 \pm 8.6$ & 0.125 \\
\hline Glucose (mg/dL) & $90.1 \pm 7.7$ & $91.0 \pm 16.7$ & $88.2 \pm 6.1$ & $95.6 \pm 6.9$ & 0.471 \\
\hline $\mathrm{SAP}(\mathrm{mmHg})$ & $187.9 \pm 12$ & $179.7 \pm 13$ & $192.8 \pm 9$ & $188.9 \pm 17$ & 0.119 \\
\hline Heart Rate (bpm) & $309.3 \pm 29.9$ & $315.7 \pm 30.1$ & $317.6 \pm 23.7$ & $327.8 \pm 15.8$ & 0.871 \\
\hline Pre-AMI ET (km/h) & $1.45 \pm 0.3$ & $1.44 \pm 0.3$ & $1.48 \pm 0.2$ & $1.50 \pm 0.1$ & 0.790 \\
\hline Exercise session $(\mathrm{km} / \mathrm{h})$ & $\longrightarrow$ & $1.41 \pm 0.3$ & $\longrightarrow$ & $1.38 \pm 0.2 \ddagger$ & 0.208 \\
\hline AMI circumference $(\%)$ & $\longrightarrow$ & $\longrightarrow$ & $42.86 \pm 4.6$ & $43.16 \pm 3.8$ & 0.890 \\
\hline Cardic output (mL/min) & $58.3 \pm 9.2$ & $56.1 \pm 15.7$ & $28.4 \pm 7.7 * \dagger$ & $30.3 \pm 9.2 * \dagger$ & $<0.001$ \\
\hline Ejection fraction $(\%)$ & $47.1 \pm 2.0$ & $52.5 \pm 5.5$ & $18.6 \pm 6.7 * \dagger$ & $25.7 \pm 8.2 * \dagger$ & $<0.001$ \\
\hline LVSF (\%) & $35.3 \pm 5.5$ & $40.8 \pm 8.2$ & $9.7 \pm 2.6^{* \dagger}$ & $13.6 \pm 5.2^{*} \dagger$ & $<0.001$ \\
\hline
\end{tabular}

SE: sham-operated rats + exercise training; I: acute myocardial infarction induced by left coronary artery ligation; IE: acute myocardial infarction induced by left coronary artery ligation + exercise training. AMI: left coronary artery ligation. ET: maximal exercise test; SAP: systemic arterial pressure; LVSF: left ventricular shortening fraction. Two way ANOVA was performed followed by Bonferroni’s post-hoc test. * p $<0.05 v s \mathrm{~S}, \dagger \mathrm{p}<0.05 v s \mathrm{SE}$ and $\neq$ $\mathrm{p}=0.030$ vs "pre-MI ET".
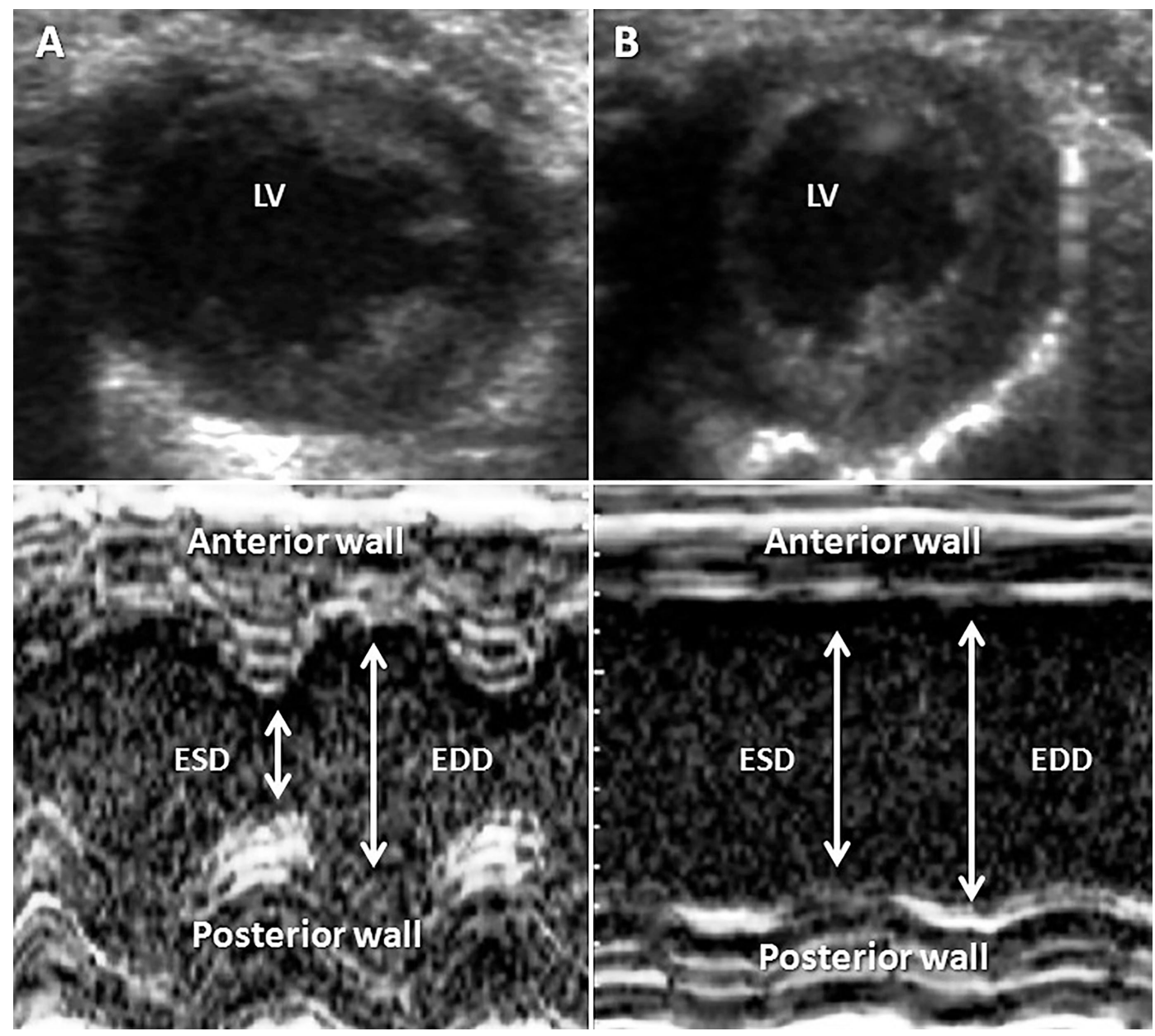

Figure 2 - Echocardiographic representation of Sham and AMI procedures. Panel A shows an animal's heart with Sham surgery and panel B shows an animal with left coronary artery ligation. The top panel shows the left ventricle in a cross section and bottom panel shows stroke and end-diastolic dimensions of the left ventricle in M module. ESD: end-systole diameter; EDD: end-diastole diameter. 


\section{Blood lactate levels during resting and maximum exercise test}
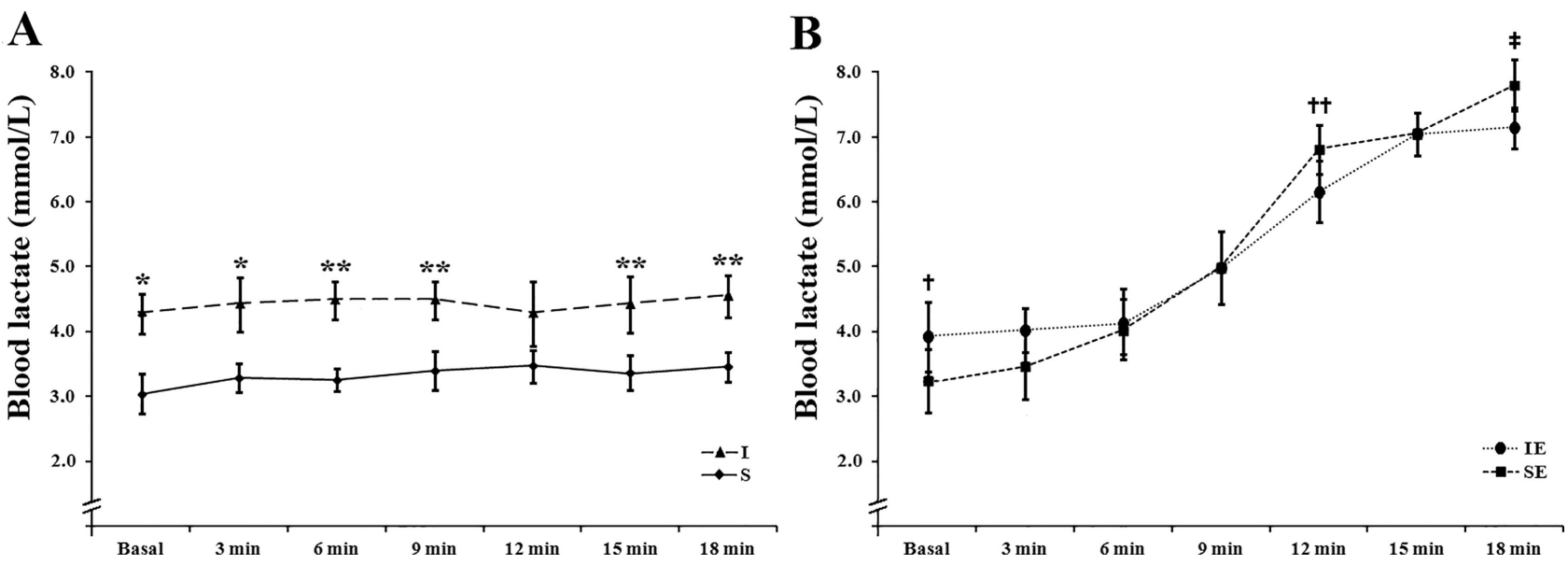

Figure 3 - Blood lactate curve during resting and an intense exercise session for the same period. S: sham-operated rats without intense exercise session; SE: sham-operated rats + intense exercise session; I: acute myocardial infarction induced by left coronary artery ligation; IE: acute myocardial infarction induced by left coronary artery ligation + intense exercise session. Two way ANOVA was performed $(\mathrm{p}<0.001)$ followed by Bonferroni's post-hoc test: Panel A (lactacidemia during resting), * $\mathrm{p}=0.001 v s$. S group and $* * \mathrm{p}<0.001$ vs. S group; Panel B (lactacidemia during an intense exercise session), $\dagger$ $\mathrm{p}=0.040$ vs. SE, $\dagger \dagger \mathrm{p}=0.042$ vs. SE and $\ddagger \mathrm{p}=0.038$ vs. SE.

$(\mathrm{p}=0.040)$, Figure 3B. Still, in the 12th minute, there was an accumulation of lactate in the SE group compared with IE $(\Delta 12.3 \%, p=0.042)$. Finally, in the 18th minute, the IE group again had lower levels of lactate when compared with the SE group $(\Delta 8.3 \%, p=0.038)$, Figure $3 \mathrm{~B}$.

Figure 4 shows the LDH-B protein levels analysis in the cardiac tissue, immediately after the maximum exercise test or rest for the same period. There were no differences between groups $(p=0.573)$. However, when the AMI factor was considered alone, LDH-B expression was lower (sham rats $v$ s AMI rats, $\mathrm{p}=0.040$ ).

\section{Discussion}

The main finding of our study is focused on the protein levels of LDH-B. Our results showed that AMI but not the exercise bout, decreased the LDH-B protein levels. Furthermore, AMI does not reduce drastically effort capa-

\section{Lactate Dehydrogenase-B}

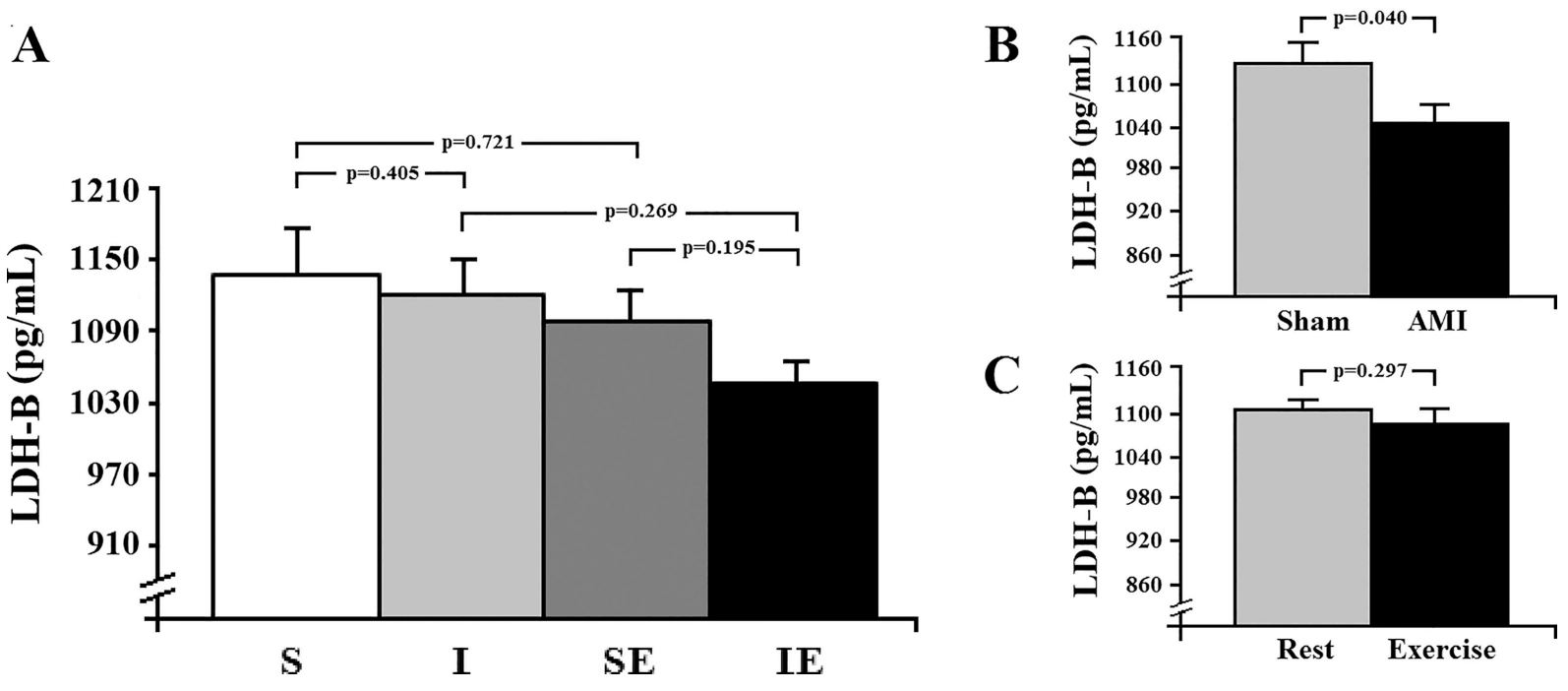

Figure 4 - Lactate Dehydrogenase-B protein levels in cardiac tissue. S: sham-operated rats without intense exercise session; SE: sham-operated rats + intense exercise session; I: acute myocardial infarction induced by left coronary artery ligation; IE: acute myocardial infarction induced by left coronary artery ligation + intense exercise session. AMI: left coronary artery ligation. Two way ANOVA was performed followed by Bonferroni's post-hoc test. Panel A shows interaction between two factors (Sham/AMI and Rest/Exercise), p(interaction)=0.573. Panel B shows only factor Sham/AMI and Panel C shows only factor Rest/Exercise. 
city nor alter the kinetics of lactate during progressive exercise, but slightly raised the blood lactate level in the resting state.

The echocardiographic parameters demonstrated that the AMI procedure resulted in similar MIs in infarcted groups (I vs IE). However, the cardiac output was lower in groups subjected to AMI, which was as expected ${ }^{20,28}$. Cardiac output is directly determined by the stroke volume and heart rate; thus, as our results showed that heart rate was similar between the study groups, it is possible to speculate that the lower stroke volume may have been caused by decreased contractility, due to the loss of cardiomyocytes after $\mathrm{AMI}^{6}$. Likewise, the LVEF was also reduced in infarcted animals when they were compared with the control animals ${ }^{29}$. Earlier evidence demonstrated that the reduction of LVEF occurs immediately after the necrosis of cardiomyocytes ${ }^{30}$, which was also observed in our study (48 $\mathrm{h}$ after AMI). The LVSF was lower in the AMI groups as well. ${ }^{31}$ found that after coronary occlusion there was a reduction in LVSF values, which were stabilized $48 \mathrm{~h}$ after the procedure until the advanced stages of cardiac remodeling and heart failure, as also found by ${ }^{30}$. In general, these observations show that a progressive loss of cardiac function occurs as a consequence of the experimental AMI, which was also observed in our study. Moreover, our results demonstrate that structural and hemodynamic effects on the heart after AMI were similar between the I and IE groups.

The experimental AMI did not reduce exercise capacity, as observed in ET when infarcted animals were compared with controls (SE group). However, the capacity of the animals was lower when it was compared with the preAMI value. It may be explained if the reduction of the absolute value is considered (SE: 1.44 vs $1.41 \mathrm{~km} / \mathrm{h}$; Table 1) in the control group. The IE group showed a reduced maximal velocity in the ET, but when compared with the SE group, which also had a slightly reduced velocity, there was no significant reduction. However, when IE animals were analyzed at different time points (pre-AMI vs post-AMI), there was a significant $(\mathrm{p}=0.03)$ reduction of $8 \%$ in ET maximal velocity. Thus, this small reduction in exercise capacity may be explained if we consider the components that determine the maximal oxygen uptake 32,33 , as the airflow and the degree of alveolar oxygen saturation, heart mechanical aspects (e.g., pre and postload values), vascular parameters (vascular complacency and blood perfusion), oxygen transport by erythrocytes and its utilization in the active muscles. Thus, even though AMI impairs cardiac function when evaluated at rest (cardiac output, left ventricular ejection fraction, shortening fraction of the left ventricle), the extent of damage to cardiomyocytes, in $96 \mathrm{~h}$ post-AMI, may not be sufficient to compromise maximal oxygen uptake.

The blood levels of lactate in infarcted animals were higher than in their respective controls. The hypothesis to explain this result could be the lower utilization of the oxidative pathway to produce energy and consequently higher dependence on the glycolytic route in group I due to reduced oxygen supply to the cardiomyocytes ${ }^{34}$. At the same time, during higher metabolic demand (during exercise sessions) in the infarcted animals, the kinetic of lactate was similar to those of the controls during most of the tests. Mainly, at 12 minutes of the protocol, the noninfarcted animals showed higher lactate levels when compared with the infarcted ones and both presented lower lactate levels than their respective controls. Thus, it seems that this is a critical aspect of the exercise test and may reflect a transition from the aerobic to the anaerobic route of predominant energy production ${ }^{35,36}$. Similarly, at the end of the test (18 minutes), the non-infarcted animals also presented raised lactate levels when compared with the infarcted ones. In the same way, in an evaluation of patients with coronary artery disease, ${ }^{37}$ observed a lower release of lactate to the bloodstream after ET on a treadmill, when these patients were compared with healthy controls at the same exercise intensity. Therefore, the lower lactate levels found in our infarcted animals may be related to a higher removal capacity. Likewise, as demonstrated previously ${ }^{38}$, a lower limb protocol of ischemic preconditioning in healthy men is associated with an attenuated rise in blood lactate concentration at the submaximal level during an incremental running test. Possibly, considering these results, the portion of noninfarcted cardiac tissue after AMI could present a higher capacity to utilize lactate to produce energy during a maximal exercise test.

With regards to the energy source of the cardiac muscle contractility, in steady-state conditions (aerobic perfusion, normal workload), the heart generates its energy mainly by oxidizing nonesterified fatty acids and the contribution of glucose is not more than $40 \%{ }^{39}$. In ischemic situations, such as in AMI, alterations in metabolic pathways ${ }^{40}$ reduce the oxidation of nonesterified fatty acids. In this case, blood lactate may represent a viable alternative. Our results did not show differences in the protein levels of cardiac LDH-B either in resting state or in maximal exercise test situations. However, when AMI factor was considered alone, LDH-B expression was lower, as it was found by $\mathrm{Li}$ et al. ${ }^{15}$ in their study where they found reduced LDH-B protein expression of among the heart tissue of infarcted rats at $4,14,28$ and 45 days after AMI (17.5, 16.1, 15.9, and $20.8 \%$ respectively). Thus, LDH-B protein levels in cardiac tissue appear to be directly associated with ischemic conditions such as AMI and they are not related to cardiac demands imposed by the intense exercise session. Differently of our data, the study of ${ }^{41}$ demonstrated higher levels of LDH-B after MI, however in their study the myocardial damage was not induced surgically, but by the administration of isoproterenol (ISO) ${ }^{41}$. The same was found in the study of ${ }^{42}$, 
also with the administration of ISO for MI induction. Nonetheless, further studies are needed evaluating the effect of exhaustive exercise on myocardial LDH-B protein levels in an animal model of surgically induced $\mathrm{MI}^{42}$.

\section{Conclusions}

The results of the present study indicated that AMI, but not the intense exercise session, decreased the LDH-B protein levels. Moreover, AMI does not reduce drastically effort capacity nor alter the kinetics of lactate during progressive exercise. Thus, the energetic issues related to harmed heart tissue as a result of AMI, apparently do not change the use of lactate as a substrate.

\section{Acknowledgements}

The authors thank Carla Finger for her English assistance. This research study was supported by the Institute of Cardiology Research Support Fund (FAPPIC).

\section{References}

1. Mendis S, Thygesen K, Kuulasmaa K, Giampaoli S, Mahonen M, Ngu Blackett K, et al. World Health Organization definition of myocardial infarction: 2008-09 revision. Int J Epidemiol. 2011; 40(1):139-46.

2. Kearney PM, Whelton M, Reynolds K, Muntner P, Whelton PK, He J. Global burden of hypertension: analysis of worldwide data. Lancet. 2005; 365(9455): 217-23.

3. Picon RV, Fuchs FD, Moreira LB, Riegel G, Fuchs SC. Trends in prevalence of hypertension in Brazil: a systematic review with meta-analysis. PLoS One. 2012; 7(10): e48255.

4. Lewington S, Clarke R, Qizilbash N, Peto R, Collins R. Age-specific relevance of usual blood pressure to vascular mortality: a meta-analysis of individual data for one million adults in 61 prospective studies. Lancet. 2002; 360(9349): 1903-13.

5. Lim SS, Vos T, Flaxman AD, Danaei G, Shibuya K, AdairRohani H, et al. A comparative risk assessment of burden of disease and injury attributable to 67 risk factors and risk factor clusters in 21 regions, 1990-2010: a systematic analysis for the Global Burden of Disease Study 2010. Lancet. 2012; 380(9859): 2224-60.

6. Pangonyte D, Stalioraityte E, Ziuraitiene R, Kazlauskaite D, Palubinskiene J, Balnyte I. Cardiomyocyte remodeling in ischemic heart disease. Medicina (Kaunas). 2008; 44(11): 848-54.

7. Pfeffer JM, Pfeffer MA, Fletcher PJ, Braunwald E. Progressive ventricular remodeling in rat with myocardial infarction. Am J Physiol. 1991; 260(5 Pt 2): H1406-14.

8. Ingwall JS. Energy metabolism in heart failure and remodelling. Cardiovasc Res. 2009; 81(3): 412-9.

9. Bing RJ, Siegel A, Ungar I, Gilbert M, Metabolism of the human heart. II. Studies on fat, ketone and amino acid metabolism. Am J Med. 1954; 16(4):504-15.

10. Lopaschuk GD, Belke DD, Gamble J, Itoi T, Schonekess BO. Regulation of fatty acid oxidation in the mammalian heart in health and disease. Biochim Biophys Acta. 1994; 1213(3): 263-76.

11. Zornoff LA, Paiva SA, Duarte DR, Spadaro J. Ventricular remodeling after myocardial infarction: concepts and clinical implications. Arq Bras Cardiol. 2009; 92(2): 150-64.

12. Schaan BD, Rabelo ER, Irigoyen MC. [Insulin: cardiovascular effects and therapeutic applications]. Arq Bras Endocrinol Metabol. 2004; 48(6): 793-802.

13. Stanley WC, Lopaschuk GD, Hall JL, McCormack JG. Regulation of myocardial carbohydrate metabolism under normal and ischaemic conditions. Potential for pharmacological interventions. Cardiovasc Res. 1997; 33(2): 243-57.

14. Markert CL, Whitt GS. Molecular varieties of isozymes. Experientia. 1968; 24(10): 977-91.

15. Li C, Qiu Q, Wang Y, Li P, Xiao C, Wang H, et al. Time course label-free quantitative analysis of cardiac muscles of rats after myocardial infarction. Mol Biosyst. 2014; 10(3): 505-13.

16. Connett RJ, Honig CR, Gayeski TE, Brooks GA. Defining hypoxia: a systems view of VO2, glycolysis, energetics, and intracellular PO2. J Appl Physiol (1985). 1990; 68(3): 83342.

17. Wasserman K. Anaerobiosis, lactate, and gas exchange during exercise: the issues. Fed Proc. 1986; 45(13): 2904-9.

18. Prathima S, Devi AS. Adaptations in lactate dehydrogenase and its isozymes in aging mammalian myocardium: interaction of exercise and temperature. Mech Ageing Dev. 1999; 108(1): 61-75.

19. Trueblood NA, Inscore PR, Brenner D, Lugassy D, Apstein CS, Sawyer DB, et al. Biphasic temporal pattern in exercise capacity after myocardial infarction in the rat: relationship to left ventricular remodeling. Am J Physiol Heart Circ Physiol. 2005; 288(1): H244-9.

20. Pfeffer MA, Pfeffer JM, Fishbein MC, Fletcher PJ, Spadaro J, Kloner RA, et al. Myocardial infarct size and ventricular function in rats. Circ Res. 1979; 44(4): 503-12.

21. Lim SS, Vos T, Flaxman AD, Danaei G, Shibuya K, AdairRohani H, et al. A comparative risk assessment of burden of disease and injury attributable to 67 risk factors and risk factor clusters in 21 regions, 1990-2010: a systematic analysis for the Global Burden of Disease Study 2010. Lancet. 2013; 380(9859): 2224-60.

22. Feng M, Whitesall S, Zhang Y, Beibel M, D’Alecy L, DiPetrillo K. Validation of volume-pressure recording tail-cuff blood pressure measurements. Am J Hypertens. 2008; 21 (12): 1288-91.

23. de Macedo Braga LM, Lacchini S, Schaan BD, Rodrigues B, Rosa K, De Angelis K, et al. In situ delivery of bone marrow cells and mesenchymal stem cells improves cardiovascular function in hypertensive rats submitted to myocardial infarction. J Biomed Sci. 2008; 15(3): 365-74.

24. Lehnen TE, Lehnen AM, Tavares AM, Bello-Klein A, Markoski MM, Machado UF, et al. Atorvastatin administered before myocardial infarction in rats improves contractility irrespective of metabolic changes. Clin Exp Pharmacol Physiol. 2014; 41(12): 986-94.

25. Peron AP, Saraiva RM, Antonio EL, Tucci PJ. [Mechanical function is normal in remanent myocardium during the healing period of myocardial infarction-despite congestive heart failure]. Arq Bras Cardiol. 2006; 86(2): 105-12. 
26. Mercier JC, DiSessa TG, Jarmakani JM, Nakanishi T, Hiraishi S, Isabel-Jones J, et al. Two-dimensional echocardiographic assessment of left ventricular volumes and ejection fraction in children. Circulation. 1982; 65(5): 962-9.

27. Lehnen AM, Leguisamo NM, Pinto GH, Markoski MM, De Angelis K, Machado UF, et al. The beneficial effects of exercise in rodents are preserved after detraining: a phenomenon unrelated to GLUT4 expression. Cardiovasc Diabetol. 2010; 9: 67.

28. Cohn JN, Ferrari R, Sharpe N. Cardiac remodeling-concepts and clinical implications: a consensus paper from an international forum on cardiac remodeling. Behalf of an International Forum on Cardiac Remodeling. J Am Coll Cardiol. 2000; 35(3): 569-82.

29. Pabis FC, Miyague NI, Francisco JC, Woitowicz V, Carvalho KA, Faria-Neto JR, et al. Echocardiographic assessment of myocardial infarction evolution in young and adult rats. Arq Bras Cardiol. 2008; 91(5): 321-6.

30. Tucci PJ. Pathophysiological characteristics of the postmyocardial infarction heart failure model in rats. Arq Bras Cardiol. 2011; 96(5): 420-4.

31. Santos L, Santos AA, Goncalves GA, Krieger JE, Tucci PJ. Bone marrow cell therapy prevents infarct expansion and improves border zone remodeling after coronary occlusion in rats. Int J Cardiol. 2010; 145(1): 34-9.

32. Brooks GA. Anaerobic threshold: review of the concept and directions for future research. Med Sci Sports Exerc. 1985; 17(1): 22-34.

33. Brooks GA, Wolfel EE, Groves BM, Bender PR, Butterfield GE, Cymerman A, et al. Muscle accounts for glucose disposal but not blood lactate appearance during exercise after acclimatization to 4,300 m. J Appl Physiol (1985). 1992; 72 (6): 2435-45.

34. Alpert JS, Thygesen K, Antman E, Bassand JP. Myocardial infarction redefined-a consensus document of The Joint European Society of Cardiology/American College of Cardiology Committee for the redefinition of myocardial infarction. J Am Coll Cardiol. 2000; 36(3): 959-69.

35. Almeida JA, Petriz Bde A, da Costa Gomes CP, Pereira RW, Franco OL. Assessment of maximal lactate steady state during treadmill exercise in SHR. BMC Res Notes. 2012; 5: 661.

36. Mader A, Heck H. A theory of the metabolic origin of "anaerobic threshold". Int J Sports Med. 1986; 7 Suppl 1: 45-65.
37. Barthelemy JC, Roche F, Gaspoz JM, Geyssant A, Minini P, Antoniadis A, et al. Maximal blood lactate level acts as a major discriminant variable in exercise testing for coronary artery disease detection in men. Circulation. 1996; 93(2): 246-52.

38. Bailey TG, Jones H, Gregson W, Atkinson G, Cable NT, Thijssen DH. Effect of ischemic preconditioning on lactate accumulation and running performance. Med Sci Sports Exerc. 2012; 44(11): 2084-9.

39. Taegtmeyer H, Hems R, Krebs HÁ. Utilization of energyproviding substrates in the isolated working rat heart. Biochem J. 1980; 186(3): 701-11.

40. Dyck JR, Cheng JF, Stanley WC, Barr R, Chandler MP, Brown $\mathrm{S}$, et al. Malonyl coenzyme a decarboxylase inhibition protects the ischemic heart by inhibiting fatty acid oxidation and stimulating glucose oxidation. Circ Res. 2004; 94(9): e78-84.

41. Priscilla DH, Prince OS. Cardioprotective effect of gallic acid on cardiac troponin-T, cardiac marker enzymes, lipid peroxidation products and antioxidants in experimentally induced myocardial infarction in Wistar rats. Chem Biol Interact. 2009; 179(2-3):118-24.

42. Punithavathi VR, Stanely Mainzen Prince P. The cardioprotective effects of a combination of quercetin and alphatocopherol on isoproterenol-induced myocardial infarcted rats. J Biochem Mol Toxicol. 2011; 25(1): 28-40.

\section{Corresponding author}

Dr. Maximiliano Schaun Instituto de Cardiologia do Rio Grande do Sul. Unidade de Pesquisa Av. Princesa Isabel, 395, Santana. CEP 90620 001. Porto Alegre, RS, Brasi. E-mail: dr.maxschaun@gmail.com

Manuscript received on August 21, 2019

Manuscript accepted on October 29, 2019

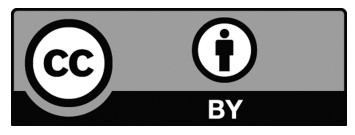

Motriz. The Journal of Physical Education. UNESP. Rio Claro, SP, Brazil - eISSN: 1980-6574 - under a license Creative Commons - Version 4.0 